\title{
Urinary Leakage
}

National Cancer Institute

\section{Source}

National Cancer Institute. Urinary Leakage. NCI Thesaurus. Code C118167.

Extravasation of urine outside the urinary collecting system. 